\title{
Variations in phyllosphere microbial community along with the development of angular leaf-spot of cucumber
}

Luyun Luo ${ }^{1,2+}$, Zhuo Zhang ${ }^{2+}$, Pei Wang ${ }^{2}$, Yongqin $\mathrm{Han}^{2}$, Decai $\mathrm{Jin}^{3}$, Pin Su², Xinqiu Tan ${ }^{1}$, Deyong Zhang ${ }^{1}$, Hamid Muhammad-Rizwan ${ }^{2}$, Xiangyang Lü ${ }^{*^{*}}$ and Yong Liu ${ }^{2^{*}}$

\begin{abstract}
The phyllosphere is colonized by a wide variety of microorganisms including epiphytes, plant-pathogenic fungus, bacteria, as well as human or animal pathogens. However, little is known about how microbial community composition changes with the development of angular leaf-spot of cucumber. Here, 18 mixed samples were collected based on the lesion coverage rate (LCR) of angular leaf-spot of cucumber from three disease severity groups (DM1: symptomatic-mild, DM2: symptomatic-moderate, DM3: symptomatic-severe). In our study, the microbial community structure and diversity were examined by Illumina MiSeq sequencing. A significant differences was observed in a diversity and community structure among three disease severity groups. The phyllosphere microbiota was observed to be dominated by bacterial populations from Proteobacteria, Actinobacteria, and Firmicutes, as well as fungal species from Ascomycota and Basidiomycota. In addition, some plant-specific microbe such as Sphingomonas, Methylobacterium, Pseudomonas, and Alternaria showed significant changes in their relative abundance of population. The LCR was correlated negatively with Sphingomonas, Methylobacterium, Quadrisphaera, and Lactobacillus, whereas correlated positively with Pseudomonas and Kineococcus $(p<0.05)$. The LCR was negatively correlated with Alternaria and Arthrinium of the fungal communities $(p<0.05)$. Molecular ecological networks of the microbial communities were constructed to show the interactions among the OTUs. Our current results indicated that the competitive relationships among species were broken with the development of angular leaf-spot of cucumber. The microbial community composition changed over the development of angular leaf-spot of cucumber. The result of molecular ecological networks indicated that the overall bacterial community tends toward mutualism from the competition. The development of angular leaf-spot of cucumber affected the ecosystem functioning by disrupting the stability of the microbial community network. This work will help us to understand the host plant-specific microbial community structures and shows how these communities change throughout the development of angular leaf-spot of cucumber.
\end{abstract}

Keywords: Phyllosphere, Microbial community, Lesion coverage rate, a Diversity, Plant-specific microbe

\footnotetext{
*Correspondence: xiangyangcn@163.com; haoasliu@163.com

†Luyun Luo and Zhuo Zhang contributed equally to this work

${ }^{1}$ College of Bioscience \& Biotechnology, Hunan Agricultural University,

Changsha, China

${ }^{2}$ Key Laboratory of Pest Management of Horticultural Crops

of Hunan Province, Hunan Plant Protection Institute, Hunan Academy

of Agricultural Science, Changsha, China

Full list of author information is available at the end of the article
} 


\section{Introduction}

Vegetables not only act as energy regulators for human, but also a major part of the human diet with great nutritive values. More than a decade ago, cucumbers were planted in an area of around 156,300 ha around the world with a total production of 26,582 tons (Ram 2002). Cucumber yield and quality are affected by many fungal, bacterial and viral diseases. The angular leaf spot caused by Pseudomonas syringae pv. lachrymans (Young et al. 1978), is distributed worldwide and caused heavy economic losses under favorable climatic conditions by decreasing the yield as well as the quality of the cucumber (Pohronezny et al. 1977).

The phyllosphere is colonized by specific microbial communities as a vital plant-associated habitat (Vorholt 2012; Bringel and Couée 2015). Leaves of plant are colonized by potential microbial communities including bacteria, fungi, protists, and viruses. There are numbers of bacteria colonizing in leaf surface ranging from $10^{6}$ to $10^{7}$ per $\mathrm{cm}^{2}$ (Vorholt 2012). The phyllosphere may form complex microbial consortia that can be beneficial, pathogenic, or antagonistic for the host plant, and contribute greatly to plant health and yield through complex plant-microbial interactions (Vorholt 2012; Bulgarelli et al. 2013; Brader et al. 2017). The phyllosphere microbial community structure were affected strongly due to changes in the relative abundance of those "key" microbes induced by abiotic or biotic factors. For example, it can be influenced by the plant species, season, geographical location, and different environmental conditions (Whipps et al. 2008; Knief et al. 2010; Wellner et al. 2011; Rastogi et al. 2012; Copeland et al. 2015; Ding and Melchner 2016).

Phyllosphere microbes can affect host fitness through the production of plant hormones and protection from pathogen colonization (Innerebner et al. 2011; Ritpitakphong et al. 2016). In order to adapt to host plants, phyllosphere microorganisms can affect community diversity and plant population (Clay and Holah 1999; Bradley et al. 2008), as well as ecosystem functions (Rodriguez et al. 2009; McGuire and Treseder 2010; Allison and Treseder 2011). The pathogens are expected to compete with native plant-associated microbes when they reach plant surfaces (Brandl et al. 2013). At the same time in the phyllosphere, these microbes will also face harsh environmental conditions including nutrient limitations, UV radiation, as well as lack of free water availability (Colla et al. 2017). All host plants are capable of activating an effective generic defense response against a wide range of microbes (Pieterse et al. 2014). Consequently, microbes usually have specialized structure to help them move towards the plant surfaces. Although the microbial community structure in the leaves has been elucidated, there is still a lack of knowledge about microbial interactions among microbial composition (Hacquard and Schadt 2015). In particularly, it remains unclear that how the establishment of microbial community were affected by competition and mutualism among microbes. It is likely that members of the microbial communities associated with plant have evolved complex strategies for interacting in complex microbial communities to maintain specific host niches.

At present, the research is mainly focused on the culturable part of leaf microflora but it is limited on the understanding of the functional traits of phyllosphere microbes. With the development of next-generation sequencing technology and related computational analysis tools, we can now perform the further investigations (Bulgarelli et al. 2012; Lundberg et al. 2012). The previous studies indicated that the bacterial communities of different plant species are plant-host dependent (Knief et al. 2010; Redford et al. 2010; Vorholt 2012). These findings suggested that the plant host and colonizers might have a selection for each other. However, the underlying processes of microbial population dynamics remain to be elucidated. In this study, our aim was to (1) compare the inter-individual and inter-specific variation of phyllosphere microbial communities; (2) characterize the composition of phyllosphere microbial communities at different disease severities of angular leaf-spot of cucumber; and (3) determine the correlation between disease severity of angular leaf-spot of cucumber and phyllosphere population.

\section{Materials and methods \\ Experimental design}

The experiment was performed in the base of LangLi town, Changsha, Hunan Province, China $\left(28^{\circ} 16^{\prime} 92^{\prime \prime} \mathrm{N}\right.$, $113^{\circ} 14^{\prime} 29^{\prime \prime} \mathrm{E}$ ) during June 2016. The cucumber (Suyan 10) was planted in six adjacent greenhouses, damaged by angular leaf-spot of cucumber for a long time. Leaf samples were collected from cucumber (Suyan 10) plants based on the proportion of lesion area of angular leaf-spot of cucumber $(0<\mathrm{DM} 1<30 \%, 30 \%<\mathrm{DM} 2<50 \%$ and DM3 $>50 \%$ ). The applied classification method of disease severity was according to the National standard in China (GB/T 17980.30-2000) with slight modifications. According to three different disease severities, 10 cucumber leaves of same disease severity with the same size at the fruiting stage were collected by five-point sampling method in each greenhouse, respectively. Then the leaf samples of same disease severity from the same greenhouse were mixed and transferred to the laboratory at refrigerated temperature. For each leaf, sampling was done by using five-point sampling within an area 
of $40 \mathrm{~m}^{2}$. Every sterile bag contained 10 leaves which were cut into tiny pieces and mixed before subsequent processing. The phyllosphere microbes were collected as described by Xie et al. reported (Xie et al. 2015; Delmotte et al. 2009; Redford and Fierer 2009), with slight modifications. In brief, $10 \mathrm{~g}$ of leaves were submerged in a $250 \mathrm{~mL}$ sterile conical flask with $100 \mathrm{~mL}$ of PBS containing $0.01 \%$ Tween-80. The flask was then shaken at $250 \mathrm{rpm}$ for $30 \mathrm{~min}$ at $28^{\circ} \mathrm{C}$, and subjected to ultrasonicsolid for $10 \mathrm{~min}$. The microbes were filtered by a $0.22 \mu \mathrm{m}$ filter microfiltration membrane using the air pump filtration, and were stored at $-80{ }^{\circ} \mathrm{C}$ for subsequent DNA extraction.

\section{DNA extraction and purification}

DNA was extracted from phyllosphere samples according to the manufacturer's protocol using the MP FastDNA ${ }^{\circledR}$ SPIN Kit for soil (MP Biochemicals, Solon, OH, USA). PCR amplicon libraries concentration were diluted to $30 \mathrm{ng} / \mu \mathrm{L}$ for each sample. The V5-V6 region of the bacterial $16 \mathrm{~S}$ rRNA gene was amplified by using the specific primer 799F (AACMGGATTAGATACCCKG) and 1115R(AGGGTTGCGCTCGTTG). The eukaryotic primers gITS7 (5'-GTGARTCATCGARTCTTTG-3') (Ihrmark et al. 2012) and ITS4 (5'-TCCTCCGCTTAT TGATATGC-3') (White et al. 1990) with a unique $6 \mathrm{nt}$ barcode were included as the modification in the forward and reverse primer, respectively. The bacterial and fungal ITS regions were amplified as previously described by Kong et al. $(2018,2019)$. PCR products were purified with an E.Z.N.A. ${ }^{\circledR}$ Gel Extraction Kit, pooled in equimolar amounts using Qubit (CA, USA). And mixed PCR products were sequenced $(2 \times 250 \mathrm{bp})$ on an Illumina MiSeq platform by ANNOROAD Gene Technology Co., Ltd. (Beijing, China) according to standard protocols.

\section{Processing of sequencing data}

Raw sequence data reads were processed with an inhouse pipeline (http://mem.rcees.ac.cn:8080) which includes a series of bioinformatics tools. In brief, a separate sample was generated according to different 12-bp barcodes and primers, allowing for one mismatch. Pairedend reads with at least $30 \mathrm{bp}$ overlap were combined by the FLASH program (Magoc and Salzberg 2011). The combined sequences (quality score $<20$ ) were filtered by Btrim program (Kong 2011). Then the sequences with either an ambiguous base or $<200 \mathrm{bp}$ were discarded. The UPARSE algorithms were used to detect and remove chimera sequences (Edgar 2013). Low abundance OTUs $(\leq 1$ count) were eliminated from the OTU table which was clustered and generated at a $97 \%$ similarity from all sequences. The microbial representative sequences for each OTU were assigned to taxonomic groups using the
RDP Classifier database (Silva database 132 version) and UNITE database (Version 12.01.2017) (Abarenkov et al. 2010), respectively. The data were resampled randomly with the lowest sequence number $(10,217$ for bacteria and 13,342 sequences for fungi). The resampled OTU table was used for the subsequent analysis. In this study, all the microbial raw sequences were deposited in the SRA database short-read archive PRJNA503587.

\section{Network construction and analysis}

Phylogenetic molecular ecological networks (pMENs) of the three groups (DM1, DM2 and DM3) were constructed based on the Spearman rank correlation matrix using by molecular ecological network analysis pipeline (MENA, http://ieg4.rccc.ou.edu/mena/login.cgi) (Deng et al. 2012; Zhou et al. 2010a, b, 2011). The process was described as Deng et al. (2012) reported. Firstly, only the OTUs appeared in more than half samples for each group were kept without log-transferring prior to obtaining the Spearman rank correlation matrix with a series of thresholds from 0.01 to 0.95 with 0.01 interval. Then only the correlations above a specific threshold ( 0.86 for bacteria and 0.92 for fungi) were kept for calculating the network eigenvalues. The network plots were visualized with the software Cytoscape 3.6.0.

\section{Statistical analysis}

The difference between $\alpha$ diversity indices (Shannon index, inverse Simpson index, richness (observed_richness), Chao's estimated richness (Chao1) and relative abundance of the taxonomic subgroups) was assessed by performing a one-way ANOVA followed by Duncan's multiple range test $(\mathrm{p}<0.05)$. Correlation analysis between lesion coverage rate (LCR) and $\alpha$ diversities along with some special genera analysis was also analyzed with Pearson, Kendall, and Spearman method. The above statistical analyses were performed using the software IBM SPSS (Version 21.0) for Windows.

Detrended correspondence analysis (DCA) were performed in subsequent analysis to compare the microbial community composition difference between two groups. Venn diagram analysis showed the shared and united OTU among three groups. The microbial community composition difference between two groups were evaluated by using Nonparametric multi-response permutation procedures (MRPP), analysis of similarities (ANOSIM) and Non-parametric permutational multivariate analysis of variance of the Adonis function (ADONIS) (Anderson 2001; Dixon 2003). The above analysis was performed using vegan package in $\mathrm{R}$ package (v.3.2.5). Analysis of fungal trophic modes annotation was performed with FunGuild (Nguyen et al. 2016). 


\section{Results}

The a diversity and community structure of microorganism under different disease severities

In this study, 18 mixed phyllosphere samples were collected and sequenced. A total of 883,665 bacterial and 657,814 ITS raw sequences were obtained from the highthroughput sequencing. After completed data analysis, these high-quality sequences were classified into 404 bacterial and 948 ITS operational taxonomy units (OTUs) at a $97 \%$ similarity level, respectively. The rarefaction curves indicated that the number of sequences for all samples reached the sequencing depths (Additional file 2: Figure S1). The $\alpha$ diversity indices including observed_richness, Chao1, Shannon index and Inverse Simpson index were shown in Fig. 1. For bacterial $\alpha$ diversity, Shannon and Inv_simpson index first increased then decreased from DM1 to DM3, while richness and Chao1 index first decreased then increased significantly. For fungal $\alpha$ diversity, all diversity indices increased from DM1 to DM2 and then decreased from DM2 to DM3; while the DM2 group showing lowest fungal diversity.

The detrended correspondence analysis (DCA) was used to measure the dissimilarity of microorganism communities among all groups (Fig. 2). In general, the microorganism community within the phyllosphere samples were clearly separated under different disease severity. In addition, the dissimilarity test also showed that differences in the phyllosphere communities among the three groups were significantly different $(\mathrm{p}<0.05)$ (Additional file 1: Table S1).

\section{The population analysis under different disease severities}

The shared and unique OTU numbers are shown in the Venn diagram (Additional file 2: Figure S2). These shared OTUs accounted for more than half the total OTUs in bacteria (232, 57.43\%) and fungi $(514,54.22 \%)$. The DM3 and DM1 group had the highest number of unique OTUs in bacterial (14.36\%) and fungal (8.54\%) microbial communities, respectively.

In totally, 13 bacterial phyla and 4 fungal phyla were detected (Additional file 2: Figure S3). Proteobacteria, Actinobacteria, and Firmicutes accounted for more than $98 \%$ of all high-quality bacterial sequences in DM1 (98.98\%), DM2 (99.34\%) and DM3 (99.17\%). While in case of fungal phyla, members from Ascomycota and Basidiomycota accounted for $89.67 \%$ (DM1), $97.06 \%$ (DM2) and 87.33\% (DM3), respectively (Additional file 2: Figure S3). At the class level, a total of 25 bacterial and 24 fungal classes were detected (Additional file 2: Figure S4).

Microbial genera with relative abundance greater than $1 \%$ are shown in Additional file 1: Table S2 and main genera are shown in Additional file 2: Figure S5. At the bacterial genus level, it was observed that the relative abundance of Quadrisphaera decreased significantly from DM1 to DM2 and then kept stable. Relative abundance of Sphingomonas and Microbacterium increased from DM1 to DM2 and then decreased from DM2 to DM3. Relative abundance of Pseudomonas increased while Methylobacterium and Curtobacterium decreased from DM1 to DM3. Relative abundance of Kineococcus kept stable from DM1 to DM2 and then increased significantly from DM2 to DM3. At the fungal genus level, it was observed that the relative abundance of Phoma and Davidiella increased slightly from DM1 to DM3 while the relative abundance of Alternaria decreased. Relative abundance of Sporobolomyces, Pseudozyma, and Aureobasidium increased from DM1 to DM2 and then decreased from DM2 to DM3.

Correlation analysis between lesion coverage rates (LCR), a diversities index and dominant genera

In case of the bacterial community, the LCR had a significant positive correlation with Observed_richness ( $\mathrm{p}<0.05$, Table 1) while had no correlation with Shannon index, Inv_Simpson index and Chao1 ( $p>0.05$, Table 1). There was no correlation between LCR and fungal diversity indices under different disease severities $(p>0.05$, Table 2). The LCR had a significant negative correlation with Sphingomonas, Methylobacterium, Quadrisphaera, Lactobacillus, whereas significant positive correlation with Pseudomonas and Kineococcus of the bacterial population ( $\mathrm{p}<0.05$, Table 1 ). Meanwhile, the LCR was negatively correlated with fungal populations of Alternaria and Arthrinium ( $<<0.05$, Table 1).

\section{Molecular ecological networks under different disease severities}

The phylogenetic molecular ecological networks (pMENs) of the bacterial and fungal communities constructed in our study to show the interactions among the OTUs are summarized in Table 3. The result suggested that many of the microbes had a few connections while only few had many connections with others. For bacterial communities, the group DM3 had the highest average connectivity (avgK:9.239) while the group DM1 had the lowest average connectivity (avgK:4.382). For fungal communities, the highest average connectivity was observed in the group DM1 (avgK:5.941) and lowest average connectivity in the group DM3 (avgK:4.432). The overall pMENs of the three groups can be visualized in Figs. 3 and 4, respectively. Modules were identified using fast greedy modularity optimization. A total 3, 8, 6 and $11,7,8$ modules with $>5$ nodes were obtained for DM1, DM2, and DM3 group in bacterial and fungal compositions, respectively. The nodes and links for all three 

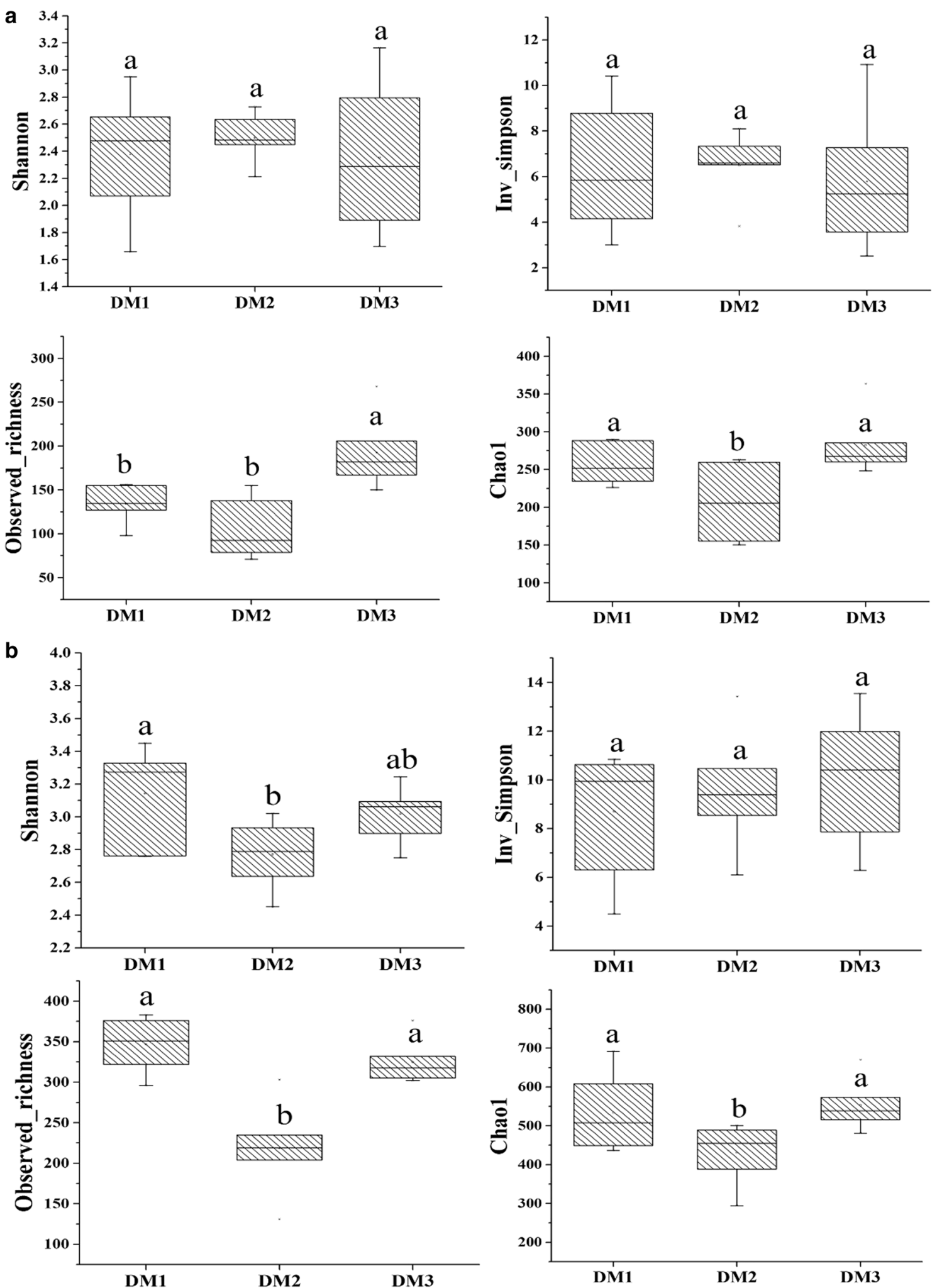

Fig. 1 Summary of a diversity indices under different disease severities. The a diversity indices including shannon, Inv_simpson indice, Observed_ richness and Chao 1 in bacteria (a) and fungi $(\mathbf{b})$. The data were analyzed based on a one-way ANOVA followed by Duncan's multiple range test at $\mathrm{p}<0.05$. DM1, DM2 and DM3 represent the three disease severities of angular leaf-spot of cucumber, respectively. DM1 symptomatic-mild, DM2 symptomatic-moderate, DM3 symptomatic-severe 


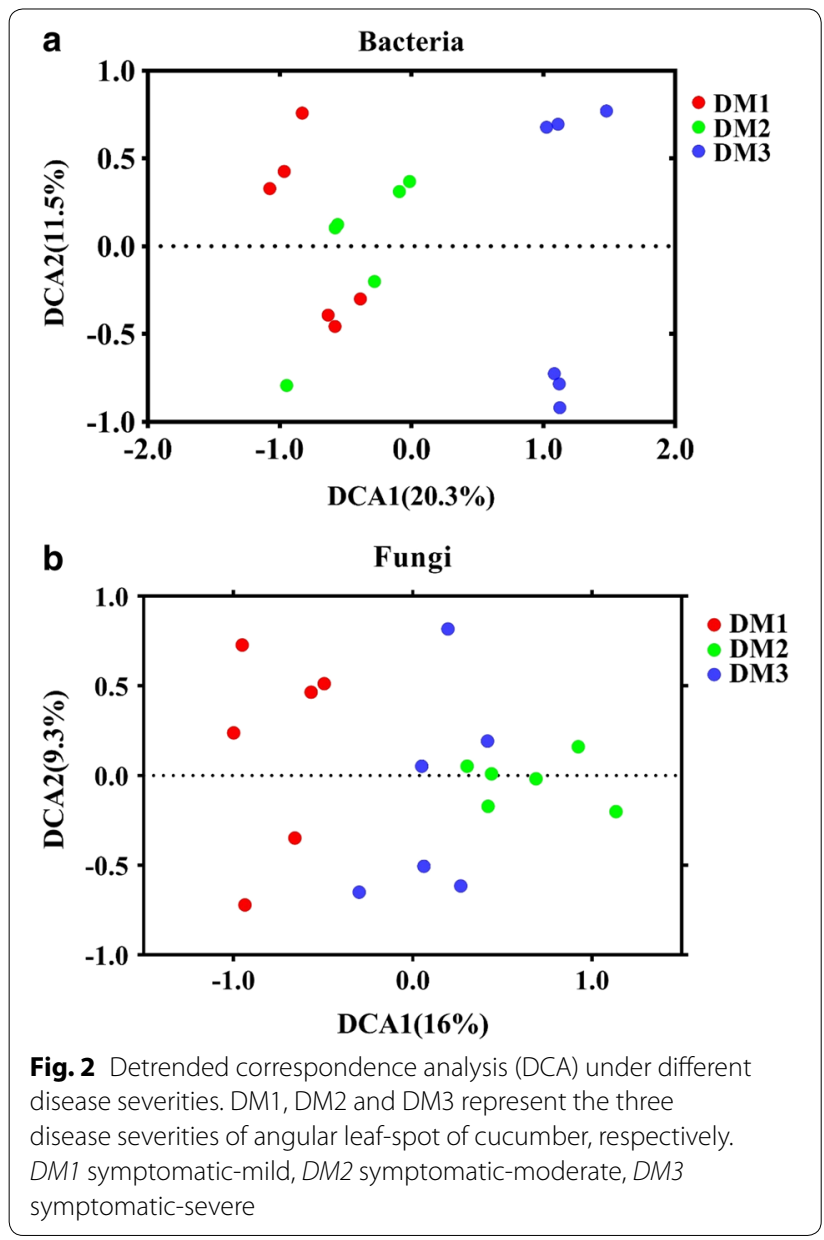

groups i.e. DM1 (306, 909), DM2 (180, 432), and DM3 $(296,656)$ were obtained in this study.

For bacterial communities, the number of the nodes in three networks belonged to phylum Actinobacteria and Proteobacteria. And most of the nodes were from Ascomycota, Basidiomycota, and some unidentified species of the fungal population. Most of the interactions between the OTUs were positive (42.16-74.4\%), and the number of positive interactions increased from DM1 to DM3 in bacteria composition. At same time, a number of negative interactions (55.1-63.26\%) were observed among fungal populations.

The topological roles of the OTUs identified in three networks are visualized in Fig. S6. The numbers of the OTUs $(97.84 \%)$ were peripherals whose links mainly stayed within their respective modules. The OTUs of bacteria $(2.09 \%)$ and fungi $(2.22 \%)$ were observed to be generalists. From bacterial communities, $0.17 \%$ of OTUs were module hubs (nodes that are connected with nodes within their modules, $\mathrm{Zi}>2.5$ ) and $1.92 \%$ of OTUs that were connectors (nodes that connected with several modules, $\mathrm{Pi}>0.62$ ). In the fungal communities, $0.42 \%$
Table 1 Correlation analysis between lesion coverage rate (LCR) and a diversities index and main genera of bacterial communities

\begin{tabular}{lccc}
\hline Factors & Pearson & Spearman & Kendall \\
\hline a Diversity & & & \\
Shannon & 0.0259 & 0.144 & 0.0528 \\
Inv_Simpson & -0.0354 & 0.03 & 0.0264 \\
Observed_richness & $0.62^{* *}$ & $0.592^{* *}$ & $0.447^{*}$ \\
Chao1 & 0.337 & 0.27 & 0.211 \\
Main bacteria genera & & & \\
Sphingomonas & $-0.513^{*}$ & $-0.562^{*}$ & $-0.396^{*}$ \\
Microbacterium & 0.103 & 0.156 & 0.0924 \\
Methylobacterium & $-0.693^{* *}$ & $-0.741^{* *}$ & $-0.568^{* *}$ \\
Curtobacterium & -0.461 & -0.361 & -0.277 \\
Pseudomonas & $0.573^{*}$ & $0.508^{*}$ & $0.383^{*}$ \\
Kineococcus & $0.623^{* *}$ & $0.673^{* *}$ & $0.436^{*}$ \\
Aureimonas & -0.289 & -0.248 & -0.146 \\
Quadrisphaera & $-0.483^{*}$ & $-0.535^{*}$ & $-0.391^{*}$ \\
Novosphingobium & $0.761^{* *}$ & $0.581^{*}$ & $0.417^{*}$ \\
Hymenobacter & -0.269 & -0.225 & -0.154 \\
Bacillus & 0.339 & 0.131 & 0.0867 \\
Lactobacillus & $-0.616^{* *}$ & $-0.718^{* *}$ & $-0.539^{* *}$ \\
\hline * & & &
\end{tabular}

${ }^{*} p<0.05,{ }^{* *} p<0.01$

Table 2 Correlation analysis between lesion coverage rate (LCR) and a diversities index and main genus of fungal communities

\begin{tabular}{lccc}
\hline Factors & Pearson & Spearman & Kendall \\
\hline a Diversity & & & \\
Shannon & -0.161 & -0.334 & -0.224 \\
Inv_Simpson & 0.186 & -0.0445 & -0.0396 \\
Observed_richness & -0.0474 & -0.202 & -0.126 \\
Chao1 & 0.191 & 0.183 & 0.172 \\
Main fungal genera & & & \\
Sporobolomyces & 0.23 & 0.377 & 0.198 \\
Davidiella & 0.396 & 0.522 & 0.37 \\
Phoma & 0.363 & 0.299 & 0.211 \\
Alternaria & $-0.564^{* *}$ & $-0.624^{* *}$ & $-0.444^{*}$ \\
Pseudozyma & 0.238 & 0.402 & 0.251 \\
Aureobasidium & -0.384 & -0.457 & -0.298 \\
Ascomycota_unidentified_1_1 & 0.136 & -0.133 & -0.066 \\
Periconia & 0.368 & 0.312 & 0.179 \\
Exobasidiomycetes_unidentified_1 & -0.229 & -0.0372 & -0.0331 \\
Pleosporales_unidentified_1 & -0.327 & -0.432 & -0.311 \\
Tremellomycetes_unidentified_1 & -0.228 & -0.406 & -0.298 \\
Chaetothyriales_unidentified_1 & -0.382 & -0.363 & -0.192 \\
Arthrinium & $-0.624^{* *}$ & $-0.613^{* *}$ & $-0.444^{*}$ \\
\hline P_0.05**P_01 & & &
\end{tabular}

${ }^{*} p<0.05,{ }^{* *} p<0.01$ 


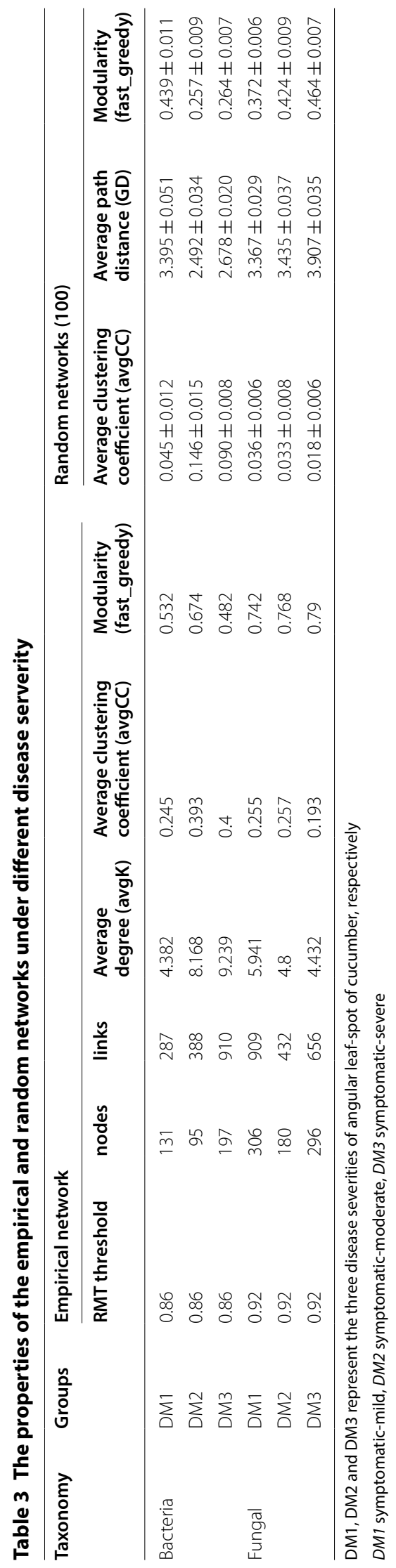


and $1.79 \%$ of OTUs were module hubs and connectors, respectively. In addition, all the module hubs were from DM2 and DM3 while all connectors were from all three groups. These OTUs associated with module hubs and connectors are shown in Additional file 1: Table S3.

\section{Discussion}

The phyllosphere is colonized by a wide variety of microorganisms including plant pathogenic microbes and other kinds of pathogens (Lindow and Brandl 2003). The colonization of phyllosphere by microbes is controlled by many factors such as factors from plants, microbes and natural environment. And these microbes can deposit on the surfaces of the leaf by means of many pathways. The microbes colonizing the leaves serving as pathogens or growth promoters may have the neutral, negative, or positive impact on their host plants (Kinkel 1997; Whipps et al. 2008). Therefore, it is crucial to study the effect of pathogens from the phyllosphere microbial communities, especially from the dominant microbiome. It is suggested that the abundance of dominant members were associated with plant-associated microbial communities and it is an important factor to determine the healthy community state (Shade and Handelsman 2012). Utilizing the beneficial potential of the plant microbiome to mitigate the hazards of major crop diseases is becoming a sustainable way to improve agricultural production (Berg et al. 2013; Gopal et al. 2013; Bakker et al. 2012). In our study, we conducted a field experiment to study the dynamic change of phyllosphere microbial communities by an Illumina MiSeq-based approach, under the different stage of angular leaf-spot of cucumber.

The phyllosphere microbiome is crucial for leaf biological processes and ecosystem functions (Ortega et al. 2016). The microbial communities composition and structure were observed to be strongly affected by the plant pathogenic microbe (Rastogi et al. 2012; Bulgari et al. 2011; Trivedi et al. 2012). In this study, the richness and Chaol of phyllosphere microbiome communities decreased significantly from DM1 to DM2, while increased significantly from DM2 to DM3 (Fig. 1). Microbial communities were observed to have the lowest biodiversity at the DM2 stage, which suggested that the pathogen caused an increase in the microbial community richness when disease pressure was higher. Generally speaking, plant disease is a serious threat to indigenous microbiome biodiversity because of its inhibitory action on other microorganisms (Zhou et al. 2010a, b). The current results are in contrast with previous research (Manching et al. 2014), who found that decreased maize leaf epiphytic bacterial richness was correlated with southern leaf blight disease severity.
Significant variations were found in the microbial community structure of phyllosphere samples at different stages of angular leaf-spot of cucumber. The result of the DCA analysis indicated that the samples from different groups were clearly separated (Fig. 2). In addition, the dissimilarity test also revealed significant differences in the composition and structure of the microbiome assembled between different groups (Additional file 1: Table S1). In previous studies, It had been observed that plant pathogenic microbes shaped the microbial communities in previous researches (Zhou et al. 2010a, b; Manching et al. 2014), but it is still unclear at different disease severities. It might be due to the differences in the disease severity of plant disease, which could select the associated microorganisms to colonize leaf surface because of the symbiotic and competitive stresses among microbial species.

The composition and structure of microbial community changes with the aggravation of the disease, there were more than half of shared OTUs were observed in each disease severities group (Additional file 2: Figure S2). However, the highest number of unique OTUs of bacteria were observed in DM3 while for fungi in DM1 (Additional file 2: Figure S2). Previous studies reported that a healthy ecological environment is usually colonized more unique OTUs (Rosenzweig et al. 2012; Zhang et al. 2018). In our study, the number of unique OTUs increased from DM1 to DM2 in bacteria while decreased significantly in fungi and observed to increase significantly from DM2 to DM3 in both bacterial and fungal communities. These results indicated that plant pathogenic microbes would stimulate the growth of more antagonistic microbes in the phyllosphere. The dominating microbial phyla were the members of Proteobacteria and Ascomycota (Additional file 2: Figure S3). Proteobacteria was the most abundant bacterial population among the three disease severities (Additional file 2: Figure S3). Among fungal communities, Ascomycota were the most abundant phylum in DM1 and DM3 groups, while Basidiomycota was the most abundant phylum in DM2 group (Fig. S3). The lesion coverage rate (LCR) were negatively correlated with Sphingomonas and Methylobacterium but positively correlated with Pseudomonas and Kineococcus $(\mathrm{p}<0.05$, Table 1$)$. It was reported that Sphingomonas contributes to plant health in many plants (Innerebner et al. 2011). In addition, some strains of Pseudomonas and Sphingomonas can enhance plant growth by producing plant growth hormones (Omer et al. 2004; Tsavkelova et al. 2007) and protect host plants from phytopathogens (Innerebner et al. 2011). Previous studies have also indicated that Methylobacterium can protect the host plants from various harmful pathogens (Ardanov et al. 2012; Madhaiyan et al. 2006). Alternaria is a plant pathogen 


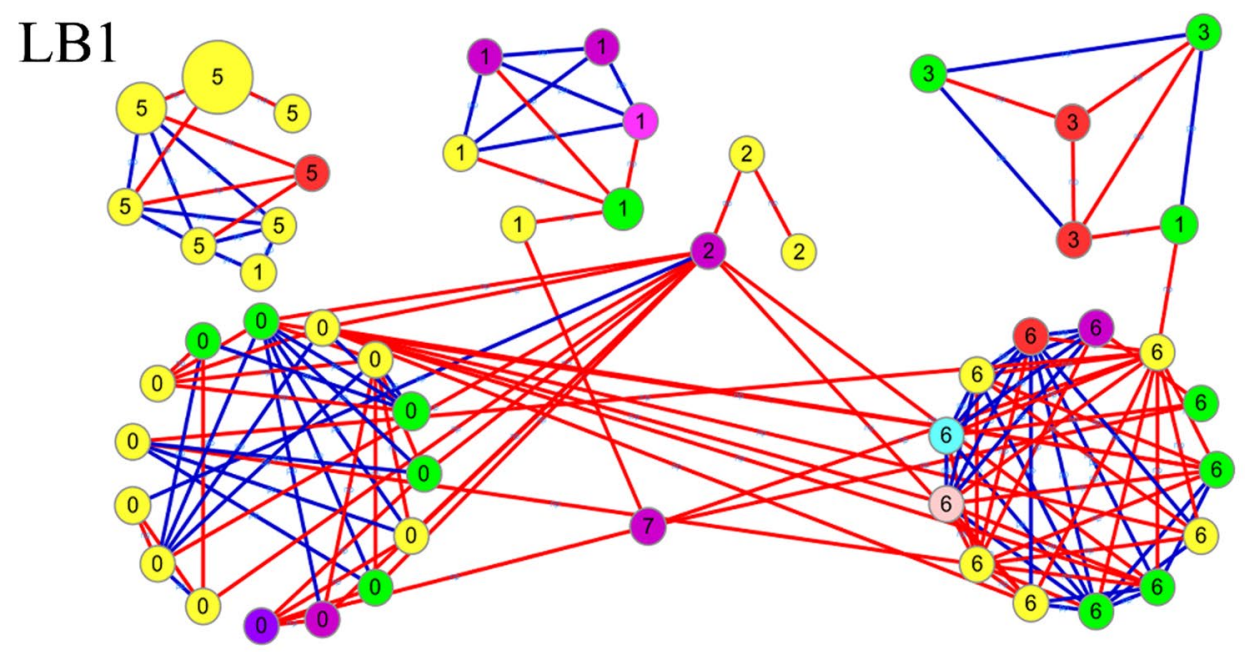

LB2

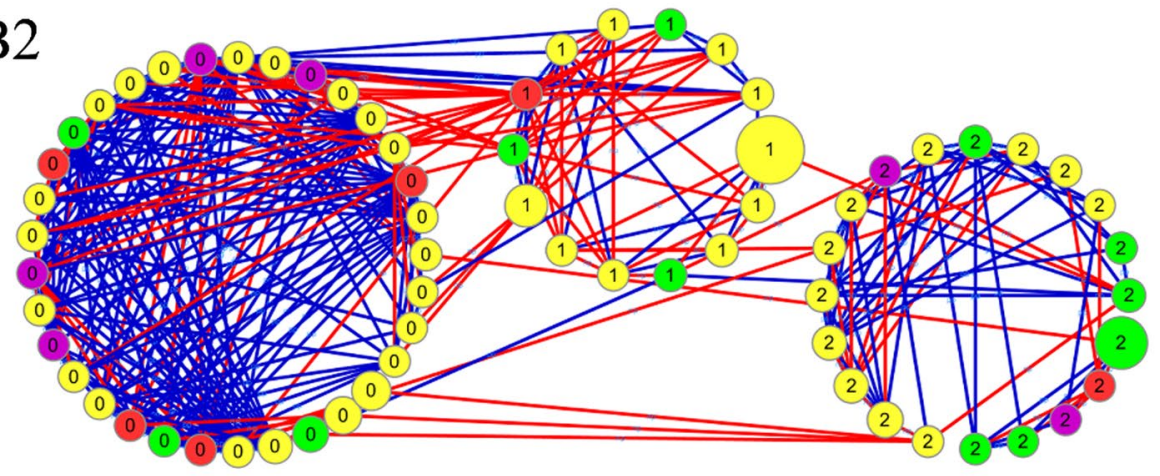

LB3
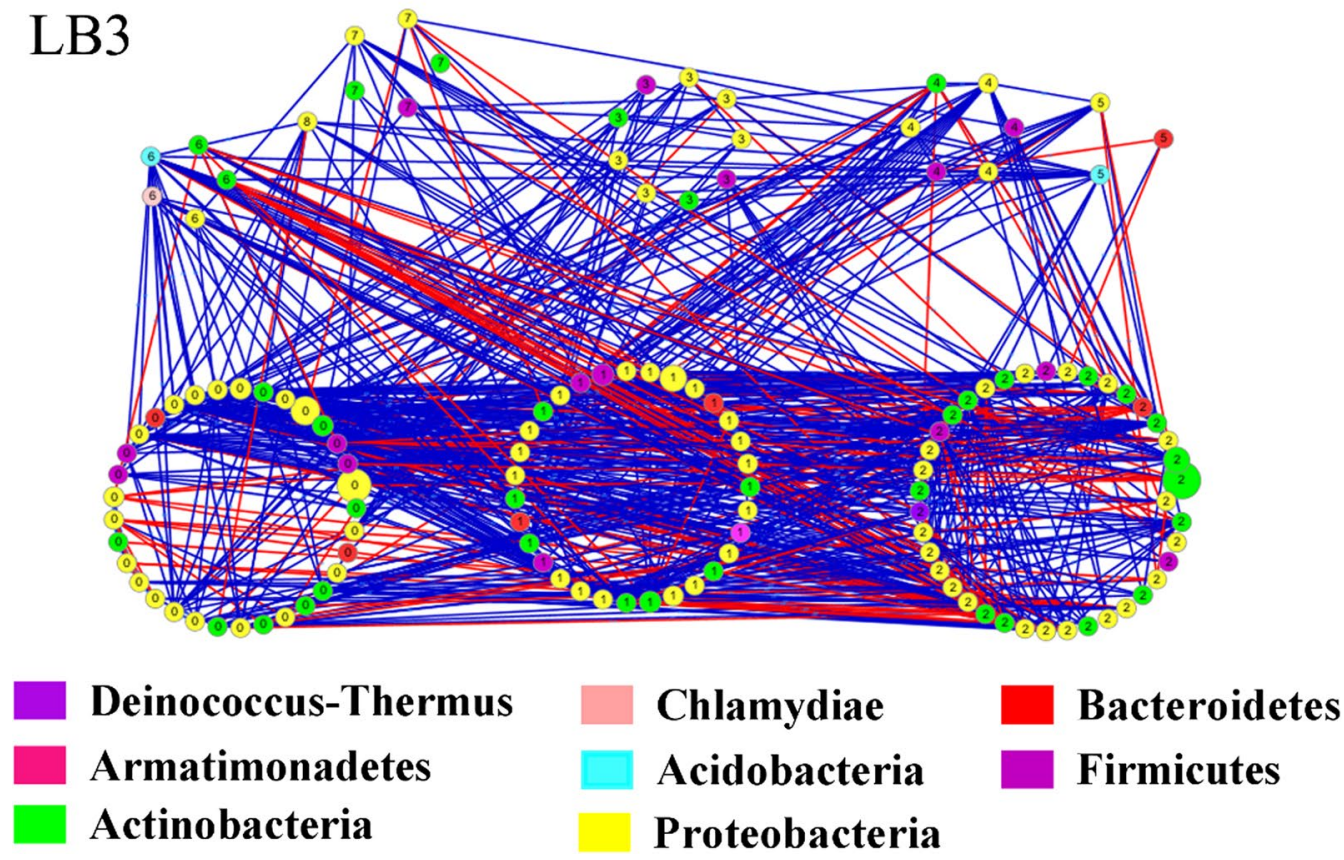

Fig. 3 Phylogenetic molecular ecological networks (pMENs) of bacterial communities under different disease severities. Modules with $>5$ nodes were obtained for bacterial groups (LB1, LB2 and LB3), respectively. The links between two nodes show the correlation (red: positive, blue: negative). The size of circle indicate the relative abundance of the OTU. The number in the center of circle represents the modules to which these OTUs belongs 


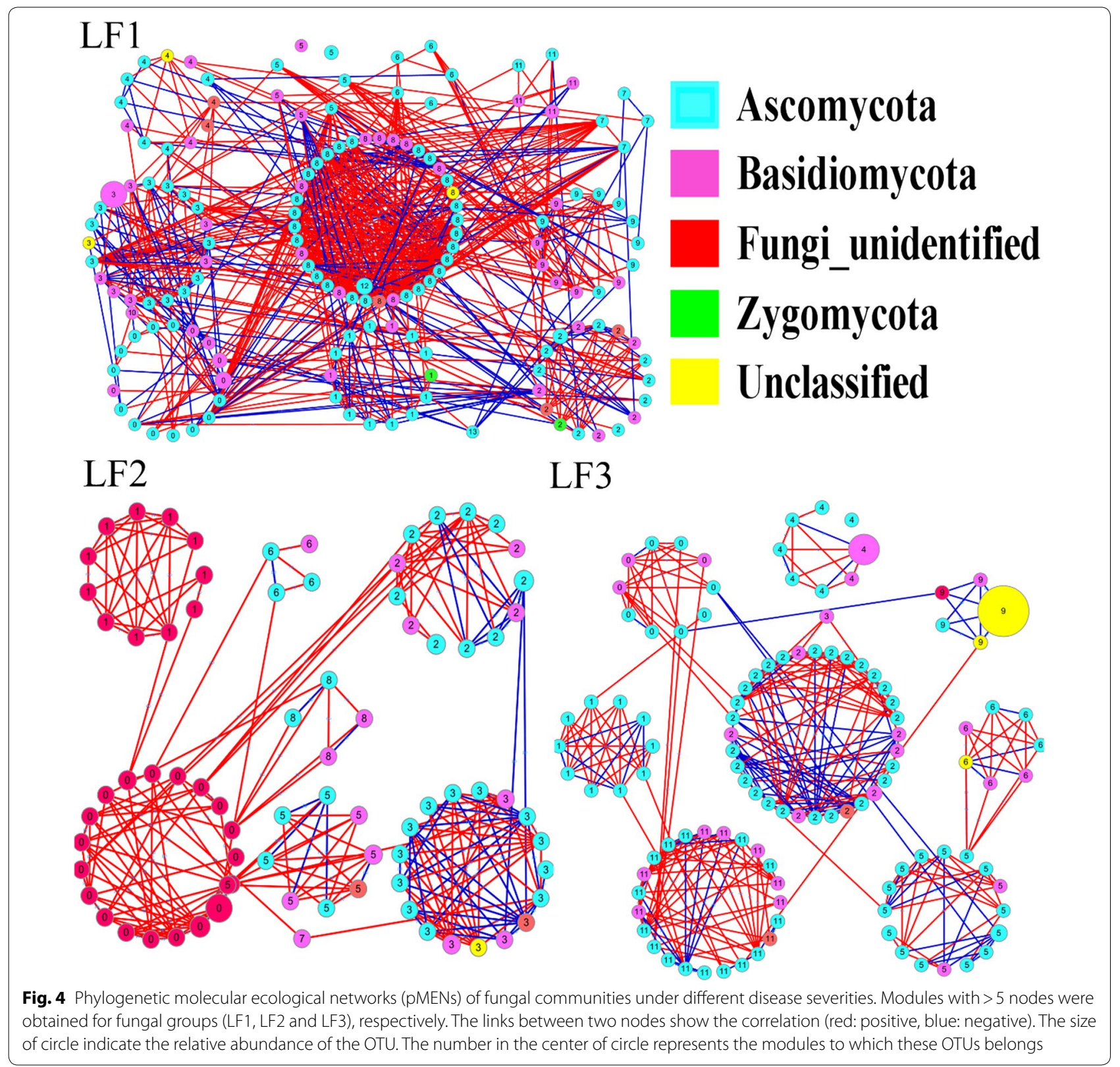

causing black spots on stems and pods of Brassica napus (Bansal et al. 1990). Relative abundance of Alternaria sp. decreased with increasing lesion coverage rate (LCR), which indicated that growth of this genus may was inhibited by the angular leaf-spot causing pathogen.

The network interactions among three different groups were also analyzed in our study. Networks based on random matrix theory could accurately reflect various complex biological systems because of stronger robustness and consistency (Zhou et al. 2011). In general, the more complex network means a more stable community structure (Liang et al. 2016; Mougi and Kondoh 2012). The results of modularity values indicated that all pMENs appear to be modular (Feng et al. 2017). The modularity values for all groups were higher than those of corresponding randomized networks (Table 3). In this study, the interspecies interaction changed with the development of angular leaf-spot of cucumber. It is obvious that the bacterial network size and the interactions, especially the number of positive links (DM1: 42.16\%, DM2: 61.34\% and DM3: 74.4\%), were significantly increased from DM1 to DM3. The results indicated that DM3 group possessed a more complex network than DM1 and DM2 group, indicating that the disease severity could affects 
the co-occurrence network patterns of overall bacterial communities. As previous studies described, positive and negative interactions usually mean mutualism and competition under environmental stress (Deng et al. 2016; Faust and Raes 2012). Interestingly, our results suggested that the competitive relationships between species were broken with the development of angular leaf-spot of cucumber. It was indicated that the overall bacterial community tends to mutualism from competition. The disease severity may just affects some modules. Therefore, the development of angular leaf-spot of cucumber could disrupt the stability of the microbial community network, which in turn affects ecosystem functioning.

\section{Additional files}

Additional file 1: Table S1. Dissimilarity test (MRPP, ANOSIM and PERMANOVA (ADONIS)) of microorganism communities in phyllosphere from two different group. DM1, DM2 and DM3 represent the three disease severities of angular leaf-spot of cucumber, respectively. DM1: symptomatic-mild, DM2: symptomatic-moderate, DM3: symptomaticsevere. Table S2. The relative abundance of main microorganism genus under different disease degree. DM1, DM2 and DM3 represent the three disease severities of angular leaf-spot of cucumber, respectively. DM1: symptomatic-mild, DM2: symptomatic-moderate, DM3: symptomaticsevere. Table S3. Summary of module hubs and connectors in microbial communities under different disease severities. LB1, LB2 and LB3 group were the bacterial population from DM1, DM2 and DM3 disease severities. LF1, LF2 and LF3 group were the fungal population from DM1, DM2 and DM3 disease severities. Module hubs were nodes that highly connected with nodes within their modules, $\mathrm{Zi}>2.5$ and connectors were nodes that connected with several modules, $\mathrm{Pi}>0.62$.

Additional file 2: Figure S1. Rarefaction curve of bacterial (A) and fungal (B) communities under different disease severities. DM1: symptomaticmild, DM2: symptomatic-moderate, DM3: symptomatic-severe. Figure S2. The unique and shared OTUs detected in the phyllosphere under different disease severities. DM1, DM2 and DM3 represent the three disease severities of angular leaf-spot of cucumber, respectively. DM1: symptomaticmild, DM2: symptomatic-moderate, DM3: symptomatic-severe. Figure S3. Relative abundance at phylum level of bacterial and fungal communities under different disease severities. DM1, DM2 and DM3 represent the three disease severities of angular leaf-spot of cucumber, respectively. DM1: symptomatic-mild, DM2: symptomatic-moderate, DM3: symptomaticsevere. Figure S4. Relative abundance at class level of bacterial and fungal communities under different disease severities. DM1, DM2 and DM3 represent the three disease severities of angular leaf-spot of cucumber, respectively. DM1: symptomatic-mild, DM2: symptomatic-moderate, DM3: symptomatic-severe. Figure S5. Relative abundance of dominant genus of bacterial and fungal communities under different disease severities. The data were analyzed based on a one-way ANOVA followed by Duncan's multiple range test at $\mathrm{p}<0.05$. DM1, DM2 and DM3 represent the three disease severities of angular leaf-spot of cucumber, respectively. DM1: symptomatic-mild, DM2: symptomatic-moderate, DM3: symptomaticsevere. Figure S6. Summary of module hubs and connectors of the bacterial (A) and fungal (B) communities under different disease severities. The OTUs were peripherals whose links mainly stayed within their respective modules. Generalists including module hubs (nodes that highly connected with nodes within their modules, Zi > 2.5) and connectors (nodes that connected with several modules, $\mathrm{Pi}>0.62$ ). LB1, LB2 and LB3 group were the bacterial population from DM1, DM2 and DM3 disease severities. LF1, LF2 and LF3 group were the fungal population from DM1, DM2 and DM3 disease severities.

\section{Abbreviations}

LCR: lesion coverage rate; DM1: symptomatic-mild; DM2: symptomatic-moderate; DM3: symptomatic-severe; MRPP: nonparametric multi-response permutation procedures; ANOSIM: analysis of similarities; ADONIS: non-parametric permutational multivariate analysis of variance of the Adonis function.

\section{Acknowledgements}

The authors are thankful to the Hunan Plant Protection Institute for their support in this experiment.

\section{Authors' contributions}

$Y L$ and $X L$ designed the experiments. $L L, Z Z$ and $Y H$ performed the experiments, XT, DJ, DZ analyzed the data, PW prepared figures and/or table, HM-R and SP revised this manuscript language. All authors read and approved the final manuscript.

\section{Funding}

This work was supported by the National Key Research Development Program of China (2017YFD0200600-002), the Natural Science Foundation of China (31601642), the Agriculture Research System of China (CARS-25-B-05), the Outstanding Talents Training Plan for Agricultural Scientific Research-Agricultural Microbial Products and Safety Production Technology of Agricultural Products, Hunan agriculture science and technology innovation fund and double firstclass construction project of Hunan Agricultural University (SYL201802002).

\section{Availability of data and materials}

The strains were available upon request. All data obtained have been included into the manuscript and its Additional files.

\section{Ethics approval and consent participate}

Not applicable.

\section{Consent for publication}

Not applicable.

\section{Competing interests}

The authors declare that they have no competing interests.

\section{Author details}

${ }^{1}$ College of Bioscience \& Biotechnology, Hunan Agricultural University, Changsha, China. ${ }^{2}$ Key Laboratory of Pest Management of Horticultural Crops of Hunan Province, Hunan Plant Protection Institute, Hunan Academy of Agricultural Science, Changsha, China. ${ }^{3}$ Chinese Academy of Sciences Key Laboratory of Environmental Biotechnology, Research Center for Eco-Environmental Sciences, Chinese Academy of Sciences, Beijing, China.

Received: 27 March 2019 Accepted: 16 May 2019

Published online: 27 May 2019

\section{References}

Abarenkov K, Nilsson RH, Larsson KH, Alexander IJ, Eberhardt U, Erland S, Høiland K, Kjøller R, Larsson E (2010) The UNITE database for molecular identification of fungi-recent updates and future perspectives. New Phytol 186(2):281-285. https://doi.org/10.1111/j.1469-8137.2009.03160.x

Allison SD, Treseder KK (2011) Climate change feedbacks to microbial decomposition in boreal soils. Fungal Ecol 4(6):362-374. https://doi. org/10.1016/j.funeco.2011.01.003

Anderson MJ (2001) A new method for non-parametric multivariate analysis of variance. Austral Ecol 26(1):32-46. https://doi.org/10.111 1/j.1442-9993.2001.01070.pp.x

Ardanov P, Sessitsch A, Häggman H, Kozyrovska N, Pirttilä AM (2012) Methylobacterium-induced endophyte community changes correspond with protection of plants against pathogen attack. PLoS ONE 7:e46802. https ://doi.org/10.1371/journal.pone.0046802

Bakker MG, Manter DK, Sheflin AM, Weir TL, Vivanco JM (2012) Harnessing the rhizosphere microbiome through plant breeding and agricultural management. Plant Soil 360:1-13. https://doi.org/10.1007/s11104-012-1361-x 
Bansal VK, Seguin-Swartz G, Rakow GFW, Petrie GA (1990) Reaction of Brassica species to infection by Alternaria brassicae. Can J Plant Sci 70(4):11591162. https://doi.org/10.4141/cjps90-139

Berg G, Zachow C, Müller H, Philipps J, Tilcher R (2013) Next-generation bio-products sowing the seeds of success for sustainable agriculture. Agronomy 3:648-656. https://doi.org/10.3390/agronomy3040648

Brader G, Compant S, Vescio K, Mitter B, Trognitz F, Ma LJ, Sessitsch A (2017) Ecology and genomic insights into plant-pathogenic and plant-nonpathogenic endophytes. Annu Rev Phytopathol 55(1):61-83. https://doi. org/10.1146/annurev-phyto-080516-035641

Bradley DJ, Gilbert GS, Martiny JB (2008) Pathogens promote plant diversity through a compensatory response. Ecol Lett 11(5):461-469. https://doi. org/10.1111/j.1461-0248.2008.01162.x

Brandl MT, Cox CE, Teplitski M (2013) Salmonella interactions with plants and their associated microbiota. Phytopathology 103(4):316-325. https://doi. org/10.1094/PHYTO-11-12-0295-RVW

Bringel F, Couée I (2015) Pivotal roles of phyllosphere microorganisms at the interface between plant functioning and atmospheric trace gas dynamics. Front Microbiol 6:486. https://doi.org/10.3389/fmicb.2015.00486

Bulgarelli D, Rott M, Schlaeppi K, Loren Ver, van Themaat E, Ahmadinejad N, Assenza F, Rauf P, Huettel B, Reinhardt R, Schmelzer E, Peplies J, Gloeckner FO, Amann R, Eickhorst T, Schulze-Lefert P (2012) Revealing structure and assembly cues for Arabidopsis root-inhabiting bacterial microbiota. Nature 488(409):91-95. https://doi.org/10.1038/nature11336

Bulgarelli D, Schlaeppi K, Spaepen S, Themaat EVLV, Schulze-Lefert P (2013) Structure and functions of the bacterial microbiota of plants. Annu Rev Plant Biol 64(1):807-838. https://doi.org/10.1146/annurev-arplant-05031 2-120106

Bulgari D, Casati P, Crepaldi P, Daffonchio D, Quaglino F, Brusetti L, Bianco PA (2011) Restructuring of endophytic bacterial communities in grapevine yellows-diseased and recovered Vitis vinifera L. plants. Appl Environ Microbiol 77(14):5018-5022. https://doi.org/10.1128/AEM.00051-11

Clay K, Holah J (1999) Fungal endophyte symbiosis and plant diversity in successional fields. Science 28 (5434):1742-1744. https://doi.org/10.1126/ science. 285.5434 .1742

Colla G, Hoagland L, Ruzzi M, Cardarelli M, Canaguier R, Rouphael Y (2017) Biostimulant action of protein hydrolysates: unraveling their effects on plant physiology and microbiome. Front Plant Sci 8:2202. https://doi. org/10.3389/fpls.2017.02202

Copeland JK, Yuan L, Layeghifard M, Wang PW, Guttman DS (2015) Seasonal community succession of the phyllosphere microbiome. Mol Plant Microbe Interact 28(3):274-285. https://doi.org/10.1094/ MPMI-10-14-0331-FI

Delmotte N, Knief C, Chaffron S, Innerebner G, Roschitzki B, Schlapbach R, von Mering C, Vorholt JA (2009) Community proteogenomics reveals insights into the physiology of phyllosphere bacteria. Proc Natl Acad Sci USA. 106(38):16428-16433. https://doi.org/10.1073/pnas.0905240106

Deng Y, Jiang YH, Yang YF, He ZL, Luo F, Zhou JZ (2012) Molecular ecological network analyses. BMC Bioinform 13(1):113. https://doi. org/10.1186/1471-2105-13-113

Deng Y, Zhang P, Qin YJ, Tu QC, Yang YF, He ZL, Warren SC, Zhou JZ (2016) Network succession reveals the importance of competition in response to emulsified vegetable oil amendment for uranium bioremediation. Environ Microbiol 18(1):205-218. https://doi.org/10.1111/1462-2920.12981

Ding T, Melchner U (2016) Influences of plant species, season and location on leaf endophytic bacterial communities of non-cultivated plants. PLoS ONE 11(3):e0150895. https://doi.org/10.1371/journal.pone.0150895

Dixon P (2003) Vegan, a package of r functions for community ecology. J Veg Sci 14(6):927-930. https://doi.org/10.1658/1100-9233(2003)014\%5b092 7:VAPORF\%5d2.0.CO;2

Edgar RC (2013) UPARSE: highly accurate OTU sequences from microbial amplicon reads. Nat Methods 10(10):996-998. https://doi.org/10.1093/ bioinformatics/btr507

Faust K, Raes J (2012) Microbial interactions: from networks to models. Nat Rev Microbiol 10(8):538-550. https://doi.org/10.1038/nrmicro2832

Feng K, Zhang Z, Cai W, Liu W, Xu M, Yin H, Wang A, He Z, Deng Y (2017) Biodiversity and species competition regulate the resilience of microbial biofilm community. Mol Ecol 26(21):6170-6182. https://doi.org/10.1111/ mec.14356
Gopal M, Gupta A, Thomas GV (2013) Bespoke microbiome therapy to manage plant diseases. Front Microbiol 4:355. https://doi.org/10.3389/fmicb .2013 .00355

Hacquard S, Schadt CW (2015) Towards a holistic understanding of the beneficial interactions across the Populus microbiome. New Phytol 205(4):1424-1430. https://doi.org/10.1111/nph.13133

Ihrmark K, Bodeker ITM, Cruz-Martinez K, Friberg H, Kubartova A, Schenck J, Strid Y, Stenlid J, Brandstrom-Durling, M, Clemmensen KE, Lindahl BD (2012) New primers to amplify the fungal ITS2 region-evaluation by 454-sequencing of artificial and natural communities. FEMS Microbiol Ecol 82(3):666-677. https://doi.org/10.1111/j.1574-6941.2012.01437.x

Innerebner G, Knief C, Vorholt JA (2011) Protection of Arabidopsis thaliana against leaf-pathogenic Pseudomonas syringae by Sphingomonas strains in a controlled model system. Appl Environ Microbiol 77(10):3202-3210. https://doi.org/10.1128/AEM.00133-11

Kinkel LL (1997) Microbial population dynamics on leaves. Annu Rev Phytopathol 35(4):327-347. https://doi.org/10.1146/annurev.phyto.35.1.327

Knief C, Ramette A, Frances L, Alonso-Blanco C, Vorholt JA (2010) Site and plant species are important determinants of the Methylobacterium community composition in the plant phyllosphere. ISME J 4(6):719-728. https ://doi.org/10.1038/ismej.2010.9

Kong Y (2011) Btrim: a fast, lightweight adapter and quality trimming program for next-generation sequencing technologies. Genomics 98:152-153. https://doi.org/10.1016/j.ygeno.2011.05.009

Kong X, Jin DC, Jin SL, Wang ZG, Yin HQ, Xu MY, Deng Y (2018) Responses of bacterial community to dibutyl phthalate (DBP) pollution in a soilvegetable ecosystem. J Hazard Mater. https://doi.org/10.1016/j.jhazm at.2018.04.015

Kong X, Jin D, Wang XX, Zhang FS, Duan GL, Liu HJ, Jia MH, Deng Y (2019) Dibutyl phthalate contamination remolded the fungal community in agro-environmental system. Chemosphere 215:189-198. https://doi. org/10.1016/j.chemosphere.2018.10.020

Liang YT, Zhao HH, Deng Y, Zhou JZ, Li GH, Sun B (2016) Long-term oil contamination alters the molecular ecological networks of Soil microbial functional genes. Front Microbiol 7:60. https://doi.org/10.3389/fmicb .2016 .00060

Lindow SE, Brandl MT (2003) Microbiology of the phyllosphere. Appl Environ Microbiol 69(4):1875-1883. https://doi.org/10.1128/ AEM.69.4.1875-1883.2003

Lundberg DS, Lebeis SL, Paredes SH, Yourstone S, Gehring J, Malfatti S, Tremblay J, Engelbrektson A, Kunin V, del Rio TG, Edgar RC, Eickhorst T, Ley RE, Hugenholtz P, Tringe SG, Dang JL (2012) Defining the core Arabidopsis thaliana root microbiome. Nature 488(7409):86-90. https://doi. org/10.1038/nature11237

Madhaiyan M, Suresh Reddy BV, Anandham R, Senthilkumar M, Poon-guzhali S, Sundaram SP, Sa T (2006) Plant growth-promoting Methylo-bacterium induces defense responses in groundnut (Arachis hypogaea L.) compared with rot pathogens. Curr Microbiol 53(4):270-276. https://doi. org/10.1007/s00284-005-0452-9

Magoc T, Salzberg SL (2011) FLASH: fast length adjustment of short reads to improve genome assemblies. Bioinformatics 27(21):2957-2963. https:// doi.org/10.1093/bioinformatics/btr507

Manching HC, Balintkurti PJ, Stapleton AE (2014) Southern leaf blight disease severity is correlated with decreased maize leaf epiphytic bacterial species richness and the phyllosphere bacterial diversity decline is enhanced by nitrogen fertilization. Front Plant Sci 5:403. https://doi.org/10.3389/ fpls.2014.00403

McGuire KL, Treseder KK (2010) Microbial communities and their relevance for ecosystem models: decomposition as a case study. Soil Biol Biochem 42(4):529-535. https://doi.org/10.1016/j.soilbio.2009.11.016

Mougi A, Kondoh M (2012) Diversity of interaction types and ecological community stability. Science 337(6092):349-351. https://doi.org/10.1126/ science. 1220529

Nguyen NH, Song Z, Bates ST, Branco S, Tedersoo L, Menke J, Schilling JS, Kennedy PG (2016) FUNGuild: an open annotation tool for parsing fungal community datasets by ecological guild. Fungal Ecol 20(1):241-248. https ://doi.org/10.1016/j.funeco.2015.06.006

Omer ZS, Tombolini R, Broberg A, Gerhardson B (2004) Indole-3-acetic acid production by pink-pigmented facultative methylotrophic bacteria. Plant 
Growth Regul 43(1):93-96. https://doi.org/10.1023/B:GROW.0000038360 .09079.ad

Ortega RA, Mahnert A, Berg C, Müller H, Berg G (2016) The plant is crucial: specific composition and function of the phyllosphere microbiome of indoor ornamentals. FEMS Microbiol Ecol 92(12):fiw173. https://doi.org/10.1093/ femsec/fiw173

Pieterse CMJ, Zamioudis C, Berendsen RL, Weller DM, Van Wees SCM, Bakker PHAM (2014) Induced systemic resistance by beneficial microbes. Annu Rev Phytopathol 52:345-347. https://doi.org/10.1146/annurev-phyto $-082712-102340$

Pohronezny K, Larsen PO, Emmatty DA, Farley JD (1977) Field studies of yield losses in pickling cucumber due to angular leaf spot. Plant Dis Report 61(5):386-390. https://doi.org/10.1007/BF00015937

Ram D (2002) Recent advances in cucurbitaceous vegetable production technology. Compendium of lectures, winter school on "recent advances in vegetable production technology". Indian Institute of Vegetable Research, Varanasi, pp 195-199

Rastogi G, Sbodio A, Tech JJ, Suslow TV, Coaker GL, Leveau JH (2012) Leaf microbiota in an agroecosystem: spatiotemporal variation in bacterial community composition on field-grown lettuce. ISME J 6(10):1812-1822. https://doi.org/10.1038/ismej.2012.32

Redford AJ, Fierer N (2009) Bacterial succession on the leaf surface: a novel system for studying successional dynamics. Microb Ecol 58(1):189-198. https://doi.org/10.1007/s00248-009-9495-y

Redford AJ, Bowers RM, Knight R, Linhart Y, Fierer N (2010) The ecology of the phyllosphere: geographic and phylogenetic variability in the distribution of bacteria on tree leaves. Environ Microbiol 12(11):2885-2893. https:// doi.org/10.1111/j.1462-2920.2010.02258.x

Ritpitakphong U, Falquet L, Vimoltust A, Berger A, Métraux JP, L'Haridon $F(2016)$ The microbiome of the leaf surface of Arabidopsis protects against a fungal pathogen. New Phytol 210(3):1033-1043. https://doi. org/10.1111/nph.13808

Rodriguez RJ, White JF Jr, Arnold AE, Redman RS (2009) Fungal endophytes: diversity and functional roles. New Phytol 182(2):314-330. https://doi.org /10.1111/j.1469-8137.2009.02773.x

Rosenzweig N, Tiedje JM, Quensen JF III, Meng Q, Hao JJ (2012) Microbial communities associated with potato common scab-suppressive soil determined by pyrosequencing analyses. Plant Dis 96(96):718-725. https ://doi.org/10.1094/PDIS-07-11-0571

Shade A, Handelsman J (2012) Beyond the Venn diagram: the hunt for a core microbiome. Environ Microbiol 14(1):4-12. https://doi.org/10.111 $1 / j .1462-2920.2011 .02585 . x$

Trivedi P, He Z, Van Nostrand JD, Albrigo G, Zhou J, Wang N (2012) Huanglongbing alters the structure and functional diversity of microbial communities associated with citrus rhizosphere. ISME J 6(2):363-383. https://doi. org/10.1038/ismej.2011.100
Tsavkelova EA, Cherdyntseva TA, Botina SG, Netrusov Al (2007) Bacteria associated with orchid roots and microbial production of auxin. Microbiol Res 162(1):69-76. https://doi.org/10.1016/j.micres.2006.07.014

Vorholt JA (2012) Microbial life in the phyllosphere. Nat Rev Microbiol 10(12):828-840. https://doi.org/10.1038/nrmicro2910

Wellner S, Lodders N, Kämpfer P (2011) Diversity and biogeography of selected phyllosphere bacteria with special emphasis on Methylobacterium spp. Syst Appl Microbiol 34(8):621-630. https://doi.org/10.1016/j.syapm .2011 .08 .005

Whipps JM, Hand P, Pink D, Bending GD (2008) Phyllosphere microbiology with special reference to diversity and plant genotype. J Appl Microbiol 105(6):1744-1755. https://doi.org/10.1111/j.1365-2672.2008.03906.x

White TJ, Bruns T, Lee S, Taylor JL (1990) Amplification and direct sequencing of fungal ribosomal RNA genes for phylogenetics. In: Innis MA, Gelfand DH, Sninsky JJ, White TJ (eds) PCR protocols: a guide to methods and applications. Academic Press, Amsterdam, pp 315-322. https://doi.org/10.1016/ B978-0-12-372180-8.50042-1

Xie WY, Su JQ, Zhu YG (2015) Phyllosphere bacterial community of floating macrophytes in paddy soil environments as revealed by illumina highthroughput sequencing. Appl Environ Microbiol 81(2):522. https://doi. org/10.1128/AEM.03191-14

Young JM, Dye DW, Bradbury JF, Panagopoulos CG, Robbs CF (1978) A proposed nomenclature and classification for plant pathogenic bacteria. N Z J Agric Res 21(1):153-177. https://doi.org/10.1080/00288233.1978.10427 397

Zhang Z, Luo LY, Tan XQ, Kong X, Yang JG, Wang DH, Zhang DY, Jin DC, Liu Y (2018) Pumpkin powdery mildew disease severity influences the fungal diversity of the phyllosphere. PeerJ 6(2):e4559. https://doi.org/10.7717/ peerj.4559

Zhou JZ, Deng Y, Luo F, He ZL, Tu QC, Zhi XY (2010a) Functional molecular ecological networks. MBio 1(4):e00169-00110. https://doi.org/10.1128/ mBio.00169-10

Zhou ZX, Jiang H, Yang C, Yang MZ, Zhang HB (2010b) Microbial community on healthy and diseased leaves of an invasive plant Eupatorium adenophorum, Southwest China. J Microbiol 48(2):139-145. https://doi. org/10.1007/s12275-010-9185-y

Zhou JZ, Deng Y, Luo F, He ZL, Yang YF (2011) Phylogenetic molecular ecological network of soil microbial communities in response to elevated $\mathrm{CO}_{2}$ MBio 2(4):e00122-00111. https://doi.org/10.1128/mBio.00122-11

\section{Publisher's Note}

Springer Nature remains neutral with regard to jurisdictional claims in published maps and institutional affiliations.

\section{Submit your manuscript to a SpringerOpen ${ }^{\odot}$ journal and benefit from:}

- Convenient online submission

- Rigorous peer review

- Open access: articles freely available online

- High visibility within the field

- Retaining the copyright to your article

Submit your next manuscript at $\boldsymbol{\nabla}$ springeropen.com 